\title{
Pre-treatment neutrophil to lymphocyte ratio as a predictive marker for pathological response to preoperative chemoradiotherapy in pancreatic cancer
}

\author{
SHINICHIRO HASEGAWA ${ }^{1,2}$, HIDETOSHI EGUCHI $^{1}$, AKIRA TOMOKUNI $^{1}$, YOSHITO TOMIMARU ${ }^{1}$, \\ TADAFUMI ASAOKA ${ }^{1}$, HIROSHI WADA ${ }^{1}$, NAOKI HAMA ${ }^{1}$, KOICHI KAWAMOTO ${ }^{1}$, SHOGO KOBAYASHI $^{1}$, \\ SHIGERU MARUBASHI ${ }^{1}$, MASAMITSU KONNNO ${ }^{2}$, HIDESHI ISHII ${ }^{2,3}$, \\ MASAKI MORI $^{1}$, YUICHIRO DOKI $^{1}$ and HIROAKI NAGANO ${ }^{1}$ \\ Departments of ${ }^{1}$ Gastroenterological Surgery, ${ }^{2}$ Frontier Science for Cancer and Chemotherapy, and \\ ${ }^{3}$ Cancer Profiling Discovery, Osaka University Graduate School of Medicine, Suita, Osaka 565-0871, Japan
}

Received October 8, 2014; Accepted July 7, 2015

DOI: $10.3892 / \mathrm{ol} .2015 .4057$

\begin{abstract}
An elevated neutrophil to lymphocyte ratio (NLR) has been reported to be associated with the pathological response to neoadjuvant therapies in numerous types of cancer. The aim of the current study was to clarify the association between pre-treatment NLR and the pathological response to preoperative chemoradiotherapy in pancreatic cancer patients. This retrospective analysis included data from 56 consecutive patients whose tumors were completely surgically resected. All patients received preoperative therapy, consisting of gemcitabine-based chemotherapy (alone or in combination with S-1) combined with 40 or 50.4 Gy irradiation, prior to surgery. Predictive factors, including NLR, platelet to lymphocyte ratio (PLR), modified Glasgow prognostic score and prognostic nutrition index, were measured prior to treatment. A comparison was made between those who responded well pathologically (good response group, Evans classification IIb/III) and those with a poor response (Evans I/IIa). NLR was determined to be significantly higher in the poor response group. Multivariate analysis identified an elevated NLR as an independent risk factor for the poor pathological response [odds ratio (OR), 5.35; $\mathrm{P}=0.0257]$. The pre-treatment $\operatorname{NLR}(\geq 2.2 /<2.2)$ was found to be a statistically significant predictive indicator of pathological response $(\mathrm{P}=0.00699)$. The results demonstrate that pre-treatment NLR may be a useful predictive marker for the pathological response to preoperative therapy in pancreatic cancer patients.
\end{abstract}

Correspondence to: Dr Hiroaki Nagano, Department of Gastroenterological Surgery, Osaka University Graduate School of Medicine, 2-2 Yamadaoka, Suita, Osaka 565-0871, Japan

E-mail: hnagano@gesurg.med.osaka-u.ac.jp

Key words: chemoradiotherapy, neoadjuvant chemotherapy, neutrophil to lymphocyte ratio, pancreatic cancer

\section{Introduction}

Pancreatic cancer has the poorest prognosis of any major malignancy (5-year survival rate, 6\%) (1). At present, surgical resection represents the only potentially curative treatment strategy in these patients, however, the 5-year survival rate following surgical resection remains low, at 5.5-21\% $(2,3)$. Gemcitabine (GEM)-based chemotherapy forms the core of multimodal therapy and has improved the prognosis of patients with pancreatic cancer (3). Multimodal therapies including preoperative treatments have been investigated, and studies indicate that preoperative chemoradiotherapy followed by surgery may improve the clinical outcome by reducing the frequency of local recurrence and increasing the 5-year survival rate in pancreatic cancer patients (4-8). However, in cases where preoperative therapy is not sufficiently effective and extensive tumor growth occurs, chemotherapy may unnecessarily increase the time between diagnosis and surgery, and may result in the patient missing the opportunity for surgical resection. Therefore, it is essential to identify the specific pre-treatment prognostic factors that can determine which patients will benefit from preoperative therapy.

To date, the identified prognostic factors predominantly consist of various pathological characteristics of the resected tumor specimen, including tumor size (9), histological grade, vascular invasion (10), lymph node metastases (11) and intrapancreatic perineural invasion (12). However, each of these factors can only be determined following surgical resection.

There is increasing evidence demonstrating that inflammatory cells in the tumor microenvironment are important in the development of tumors; blood cell counts in peripheral blood, which in part reflect immune function in cancer patients, are considered part of the internal environment (13-20). A number of prognostic factors based on cancer-associated systemic inflammation have been investigated, including the following: Serum C-reactive protein (CRP) combined with albumin levels (modified Glasgow prognostic score; mGPS) (21); Albumin level in combination with lymphocyte 
count (Onodera's prognostic nutritional index; PNI) (22); the neutrophil to lymphocyte ratio (NLR) (23), combining neutrophil and lymphocyte counts; and the platelet to lymphocyte ratio (PLR) (24), combining platelet and lymphocyte counts. However it is unknown whether such prognostic markers correlate with the outcome of preoperative therapy in pancreatic cancer patients.

The present study aimed to determine whether the presence of systemic inflammation predicts the outcome of preoperative treatments in patients with pancreatic cancer.

\section{Materials and methods}

Patient population. The present retrospective analysis included data from 56 consecutive patients with histologically confirmed pancreatic ductal adenocarcinoma, whose tumors were completely resected by surgery (R0) at Osaka University Hospital (Suita, Osaka, Japan) between March 2007 and October 2012. None of the patients had received any prior treatments, and all were newly diagnosed. During this period, patients with any T stage (cT1-4) and degree of lymph node involvement, including regional and distant lymph nodes (N1 and M1 lym), but without distant organ metastasis, received chemoradiotherapy prior to surgery. All patients had sufficient renal, hepatic, cardiac and bone marrow reserve and were able to tolerate the planned chemotherapy and subsequent surgical procedures.

The disease stages of all patients were determined prior to preoperative therapy and following surgery, according to the International Union Against Cancer criteria (25). Pre-treatment clinical staging was based on computed tomography (CT) scans of the chest and abdomen, magnetic resonance imaging, and positron emission tomography (PET) scanning. Lymph nodes measuring $\geq 1.0 \mathrm{~cm}$ in maximum transverse diameter on CT scans were diagnosed as metastasis-positive; if lymph nodes were visible but measured $<1.0 \mathrm{~cm}$, they were regarded as metastasis-positive only when the PET scan revealed focal prominent 18-fluorodeoxyglucose uptake. The study protocol was approved by the Human Ethics Review Committee of Osaka University School of Medicine. Written informed consent was obtained from all patients.

Hematological examination. Routine laboratory tests for leukocyte, neutrophil, lymphocyte, platelet, C-reactive protein (CRP), albumin, carbohydrate antigen 19-9 (CA19-9), carcinoembryonic antigen (CEA) and DUPAN-2 levels were conducted prior to surgery and the commencement of preoperative therapy. The latex immunonephelometry method was applied to measure the serum concentration of CRP (normal range, 0-0.3 mg/dl) using a JCA-BM6070 automated biochemical analyzer (JEOL Ltd., Tokyo, Japan) and CRP-EX (LSI Medience Corporation, Tokyo, Japan). The chemiluminescence enzyme immunoassay method was applied to measure serum levels of CA19-9, CEA and DUPAN-2 using Lumipulse G1200 (Fujirebio, Inc., Tokyo, Japan), Access CEA reagent and the UniCel DXI 800 immunoassay system (Beckman Coulter, Inc., Brea,CA, USA). Serum levels $<37 \mathrm{U} / \mathrm{ml}$ for CA19-9, $<5 \mathrm{ng} / \mathrm{ml}$ for CEA and $<150 \mathrm{U} / \mathrm{ml}$ for DUPAN-2 were considered as normal levels in the present study. Based on the mGPS (21), which combines CRP and albumin concentrations,
Table I. Clinicopathological characteristics of the included patients $(n=56)$.

\begin{tabular}{|c|c|}
\hline Parameter & Value \\
\hline Age (years) & $65.6 \pm 10.8$ \\
\hline \multicolumn{2}{|l|}{ Gender, n } \\
\hline Male & 34 \\
\hline Female & 22 \\
\hline White blood cells $(/ \mu 1)^{\mathrm{a}}$ & $5425.7 \pm 1450.4$ \\
\hline Neutrophil $(\%)^{\mathrm{a}}$ & $60.6 \pm 9.4$ \\
\hline Lymphocyte (\%) & $27.6 \pm 7.9$ \\
\hline Platelets $\left(10^{4} / \mu 1\right)^{\mathrm{a}}$ & $22.1 \pm 6.8$ \\
\hline C-reactive protein $(\mathrm{mg} / \mathrm{dl})^{\mathrm{a}}$ & $0.36 \pm 0.67$ \\
\hline $\operatorname{Albumin}(\mathrm{g} / \mathrm{dl})^{\mathrm{a}}$ & $3.8 \pm 0.3$ \\
\hline Carbohydrate antigen 19-9 (U/ml $)^{\mathrm{a}}$ & $328.0 \pm 391.9$ \\
\hline Carcinoembryonic antigen $(\mathrm{ng} / \mathrm{ml})^{\mathrm{a}}$ & $5.6 \pm 14.8$ \\
\hline DUPAN-2 (U/mla) & $1951.7 \pm 7451.4$ \\
\hline Neutrophil to lymphocyte ratio ${ }^{a}$ & $2.6 \pm 1.6$ \\
\hline Platelet to lymphocyte ratio ${ }^{\mathrm{a}}$ & $165.8 \pm 70.2$ \\
\hline \multicolumn{2}{|l|}{ Modified Glasgow prognostic score, $\mathrm{n}$} \\
\hline $1+2$ & 6 \\
\hline 0 & 50 \\
\hline Prognostic nutrition index ${ }^{a}$ & $44.9 \pm 4.7$ \\
\hline \multicolumn{2}{|l|}{ Location, $\mathrm{n}$} \\
\hline Pancreatic head & 47 \\
\hline Pancreatic body & 3 \\
\hline Pancreatic tail & 6 \\
\hline \multicolumn{2}{|l|}{ cT stage, $\mathrm{n}$} \\
\hline $\mathrm{T} 1$ & 3 \\
\hline $\mathrm{T} 2$ & 1 \\
\hline $\mathrm{T} 3$ & 51 \\
\hline $\mathrm{T} 4$ & 1 \\
\hline \multicolumn{2}{|l|}{$\mathrm{cN}$ status, $\mathrm{n}$} \\
\hline Positive & 4 \\
\hline Negative & 52 \\
\hline \multicolumn{2}{|l|}{ cStage, $\mathrm{n}$} \\
\hline I & 4 \\
\hline IIA & 46 \\
\hline IIB & 4 \\
\hline III & 1 \\
\hline IV & 1 \\
\hline Maximal diameter $(\mathrm{mm})^{\mathrm{a}}$ & $21.3 \pm 13.6$ \\
\hline \multicolumn{2}{|l|}{ Histology, $\mathrm{n}$} \\
\hline Well-differentiated & 1 \\
\hline Moderately differentiated & 54 \\
\hline Poorly differentiated & 1 \\
\hline \multicolumn{2}{|l|}{ pT stage, $n$} \\
\hline $\mathrm{T} 1$ & 14 \\
\hline $\mathrm{T} 2$ & 5 \\
\hline T3 & 37 \\
\hline $\mathrm{T} 4$ & 0 \\
\hline \multicolumn{2}{|l|}{$\mathrm{pN}$ status, $\mathrm{n}$} \\
\hline Positive & 17 \\
\hline Negative & 39 \\
\hline
\end{tabular}


Table I. Continued.

\begin{tabular}{lc}
\hline Parameter & Value \\
\hline pStage, $\mathrm{n}$ & \\
I & 14 \\
IIA & 26 \\
IIB & 15 \\
III & 0 \\
IV & 1 \\
Evans grade, $\mathrm{n}$ & \\
I & 10 \\
IIa & 30 \\
IIb & 14 \\
III & 2 \\
Adjuvant therapy, $\mathrm{n}$ & 42 \\
Yes & 14 \\
No & \\
Recurrence, $\mathrm{n}$ & 34 \\
Yes & 22 \\
No & \\
\hline a Data presented as mean \pm standard deviation. T, tumor invasion \\
depth; N, lymph node metastasis. \\
\hline
\end{tabular}

patients who had both elevated CRP levels $(>1 \mathrm{mg} / \mathrm{dl})$ and albumin levels $<3.5 \mathrm{~g} / \mathrm{dl}$ were assigned a score of 2 . Patients with only elevated CRP ( $>1 \mathrm{mg} / \mathrm{dl})$ were assigned a score of 1. Patients with neither of these abnormalities were assigned a score of 0 . The PNI was calculated using the following formula: PNI $=$ [albumin $(\mathrm{g} / \mathrm{dl}) \times 10]+[0.005 \mathrm{x}$ total lymphocyte count $(/ \mu 1)](22,26)$.

Preoperative therapy and postoperative follow-up. The preoperative treatment consisted of GEM-based chemotherapy [GEM alone $\left(600-1,000 \mathrm{mg} / \mathrm{m}^{2}\right)$ or GEM plus $\mathrm{S}-1\left(60-80 \mathrm{mg} / \mathrm{m}^{2}\right)$, a fourth-generation oral fluoropyrimidine] combined with 40 or 50.4 Gy irradiation, as reported previously $(4,27)$. Based on the CONKO-001 study (3), gemcitabine-based adjuvant chemotherapy has been routinely administered since 2007. Postoperative follow-up consisted of a routine physical examination and laboratory tests, including assessment of serum levels of CEA, CA19-9 and DUPAN-2. Chest X-ray and CT/ultrasonography of the abdomen were performed every 3 months, and the presence or absence of cancer recurrence was carefully monitored. Recurrence was defined as the detection of a new abnormal finding or the gradual enlargement of an abnormal finding during any imaging study. The median follow-up period of the 56 patients was 27.1 months (range, 6.1-80.2 months).

Evaluation of response to preoperative therapies. The preoperative treatment effect was determined based on the examination of hematoxylin-eosin (Sigma-Aldrich, St. Louis, MO, USA) stained permanent sections by a gastrointestinal pathologist; samples were scored using a previously published grading system, Evans classification (28). A minimal pathological response was defined as a treatment effect score of grade I or grade IIa ( $\geq 90 \%$ or $50-89 \%$ viable tumor cells, respectively,
Table II. Comparison of clinical and histopathological factors between poor response group (Evans I+IIa) and good response group (Evans IIb+III).

\begin{tabular}{|c|c|c|c|}
\hline \multirow[b]{2}{*}{ Parameter } & \multicolumn{2}{|c|}{ Evans grade } & \multirow[b]{2}{*}{ P-value } \\
\hline & $\mathrm{I} / \mathrm{IIa}(\mathrm{n}=40)$ & IIb/III (n=16) & \\
\hline Age $(\text { years })^{\mathrm{a}}$ & $65.9 \pm 10.0$ & $64.7 \pm 12.9$ & NS \\
\hline Gender, $\mathrm{n}$ & & & NS \\
\hline Male & 25 & 9 & \\
\hline Female & 15 & 7 & \\
\hline CA19-9 (U/ml) ${ }^{\mathrm{a}}$ & $313.6 \pm 377.3$ & $365.3 \pm 439.3$ & NS \\
\hline $\mathrm{CEA}(\mathrm{ng} / \mathrm{ml})^{\mathrm{a}}$ & $6.4 \pm 17.4$ & $3.4 \pm 1.8$ & NS \\
\hline DUPAN-II (U/ml) ${ }^{\mathrm{a}}$ & $2231.2 \pm 8717.9$ & $1233.0 \pm 1971.5$ & NS \\
\hline $\mathrm{NLR}^{\mathrm{a}}$ & $2.9 \pm 1.8$ & $1.9 \pm 0.6$ & 0.0481 \\
\hline $\mathrm{PLR}^{\mathrm{a}}$ & $172.9 \pm 73.4$ & $147.3 \pm 59.2$ & NS \\
\hline mGPS, $\mathrm{n}$ & & & NS \\
\hline $1+2$ & 5 & 0 & \\
\hline 0 & 35 & 16 & \\
\hline $\mathrm{PNI}^{\mathrm{a}}$ & $44.2 \pm 4.4$ & $46.8 \pm 5.1$ & NS \\
\hline Location, $\mathrm{n}$ & & & NS \\
\hline Pancreatic head & 28 & 8 & \\
\hline Pancreatic body & 8 & 6 & \\
\hline Pancreatic tail & 4 & 2 & \\
\hline cT stage, $\mathrm{n}$ & & & NS \\
\hline $\mathrm{T} 1$ & 3 & 0 & \\
\hline $\mathrm{T} 2$ & 1 & 0 & \\
\hline $\mathrm{T} 3$ & 35 & 16 & \\
\hline $\mathrm{T} 4$ & 1 & 0 & \\
\hline $\mathrm{cN}$ status, $\mathrm{n}$ & & & NS \\
\hline Positive & 4 & 0 & \\
\hline Negative & 36 & 16 & \\
\hline cStage, n & & & NS \\
\hline I & 4 & 0 & \\
\hline IIA & 31 & 15 & \\
\hline IIB & 4 & 0 & \\
\hline III & 1 & 0 & \\
\hline IV & 0 & 1 & \\
\hline $\begin{array}{l}\text { Maximal diameter } \\
(\mathrm{mm})^{\mathrm{a}}\end{array}$ & $22.3 \pm 14.9$ & $18.8 \pm 9.4$ & NS \\
\hline Histology, $\mathrm{n}$ & & & NS \\
\hline Well & 1 & 0 & \\
\hline Moderate & 38 & 16 & \\
\hline Poor & 1 & 0 & \\
\hline pT stage, n & & & 0.0611 \\
\hline $\mathrm{T} 1$ & 7 & 7 & \\
\hline $\mathrm{T} 2$ & 3 & 2 & \\
\hline T3 & 30 & 7 & \\
\hline $\mathrm{T} 4$ & 0 & 0 & \\
\hline pN status, $\mathrm{n}$ & & & NS \\
\hline Positive & 13 & 3 & \\
\hline Negative & 27 & 13 & \\
\hline pStage, n & & & NS \\
\hline $\mathrm{I}$ & 7 & 7 & \\
\hline IIA & 20 & 6 & \\
\hline
\end{tabular}


Table II. Continued.

\begin{tabular}{|c|c|c|c|}
\hline \multirow[b]{2}{*}{ Parameter } & \multicolumn{2}{|c|}{ Evans grade } & \multirow[b]{2}{*}{ P-value } \\
\hline & $\mathrm{I} / \mathrm{IIa}(\mathrm{n}=40)$ & $\mathrm{IIb} / \mathrm{III}(\mathrm{n}=16)$ & \\
\hline \multicolumn{3}{|l|}{ pStage, $\mathrm{n}$} & NS \\
\hline IIB & 12 & 3 & \\
\hline III & 0 & 0 & \\
\hline IV & 1 & 0 & \\
\hline \multicolumn{3}{|l|}{ Adjuvant therapy, n } & NS \\
\hline Yes & 28 & 14 & \\
\hline No & 12 & 2 & NS \\
\hline \multicolumn{3}{|l|}{ Recurrence, n } & 0.0695 \\
\hline Yes & 21 & 13 & \\
\hline No & 19 & 3 & \\
\hline \multicolumn{4}{|c|}{$\begin{array}{l}\text { aData presented as mean } \pm \text { standard deviation. NS, not significant; } \\
\text { CA19-9, carbohydrate antigen 19-9; CEA, carcinoembryonic antigen; } \\
\text { NLR, neutrophil to lymphocyte ratio; PLR, platelet to lymphocyte } \\
\text { ratio; mGPS, modified Glasgow prognostic score; PNI, prognostic } \\
\text { nutrition index; Well, well-differentiated; Moderate, moderately dif- } \\
\text { ferentiated; Poor, poorly differentiated. }\end{array}$} \\
\hline
\end{tabular}

Table III. Predictive factors for the pathological response in clinical information.

A, Univariate analysis

\begin{tabular}{lcc}
\hline Variable & OR $(95 \%$ CI $)$ & P-value \\
\hline NLR $(\geq 2.2 /<2.2)$ & $6.84(1.61-47.58)$ & 0.00740 \\
mGPS $(1+2 / 0)$ & NA & 0.0407 \\
$\mathrm{cT}(\mathrm{T} 1, \mathrm{~T} 2 / \mathrm{T} 3, \mathrm{~T} 4)$ & $\mathrm{NA}$ & 0.0935 \\
$\mathrm{cN}(+/-)$ & $\mathrm{NA}$ & 0.0935
\end{tabular}

B, Multivariate analysis

\begin{tabular}{lcc}
\hline Variable & OR $(95 \% \mathrm{CI})$ & P-value \\
\hline $\mathrm{NLR}(\geq 2.2 /<2.2)$ & $5.35(1.21-38.03)$ & 0.0257 \\
$\mathrm{cT}(\mathrm{T} 1, \mathrm{~T} 2 / \mathrm{T} 3, \mathrm{~T} 4)$ & $\mathrm{NA}$ & 0.175 \\
$\mathrm{cN}(+/-)$ & $\mathrm{NA}$ & 0.175
\end{tabular}

OR, odds ratio; CI, confidence interval; NLR, neutrophil to lymphocyte ratio; mGPS, modified Glasgow prognostic score; cT, clinical tumor invasion depth; $\mathrm{cN}$, clinical node status; +, positive; -, negative; NA, not available.

remaining following therapy). Grades IIb (10-49\% viable tumor cells remaining) or III ( $<10 \%$ viable tumor cells remaining) were considered a partial pathological response. The absence of any remaining viable tumor cells, corresponding to grade IV, was considered a complete pathological response.

Statistical analysis. Data were expressed as the mean \pm standard deviation. Clinicopathological parameters were
Table IV. Association between pathological response and pretreatment NLR.

\begin{tabular}{lccc}
\hline $\begin{array}{l}\text { Pathological } \\
\text { response }\end{array}$ & $\begin{array}{c}\text { High NLR } \\
(\geq 2.2), \mathrm{n}\end{array}$ & $\begin{array}{r}\text { Low NLR } \\
(<2.2), \mathrm{n}\end{array}$ & P-value \\
\hline Evans grade I/IIa & 20 & 19 & 0.00699 \\
Evans grade IIb/III & 2 & 15 & \\
\hline
\end{tabular}

NLR, neutrophil to lymphocyte ratio.

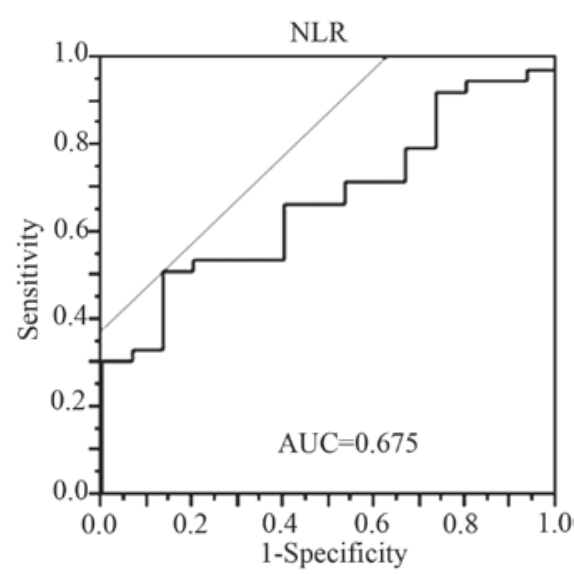

Figure 1. A receiver operating characteristic curve constructed to estimate the optimal cut-off value of the pre-treatment NLR. NLR, neutrophil to lymphocyte ratio; AUC, area under curve.

compared using the Fisher's exact test and $\chi^{2}$ test, and continuous variables were compared using a Mann-Whitney $\mathrm{U}$ test. A receiver operating characteristic (ROC) curve was constructed to estimate the optimal cut-off value of the pre-treatment NLR. A logistic regression analysis was used to analyze the simultaneous influence of predictive factors. Odds ratios (ORs) estimated from the logistic analysis were reported as relative risks with corresponding $95 \%$ confidence intervals (CIs). In all analyses, a $\mathrm{P}<0.05$ was considered to indicate a statistically significant difference. Statistical analysis was performed using JMP software version 10.0.2 (SAS Institute Inc., Cary, NC, USA).

\section{Results}

Patient characteristics. The 56 patients in the current study comprised 34 (60.7\%) males and 22 (39.3\%) females, and the mean age was $65.6 \pm 10.8$ years (range, 38-84 years). All patients who received preoperative chemoradiotherapy followed by surgery were enrolled in the study. With regard to the hematological examination, the mean NLR value among the 56 patients was $2.6 \pm 1.6$, the mean PLR value was $165.8 \pm 70.2$, and the mean PNI value was $44.9 \pm 4.7$. In 47 patients $(83.9 \%)$, the tumor was localized to the pancreatic head. Other clinical and histopathological information is listed in Table I.

Comparison of mean NLR values of the poor and good response groups. In order to assess the association between 

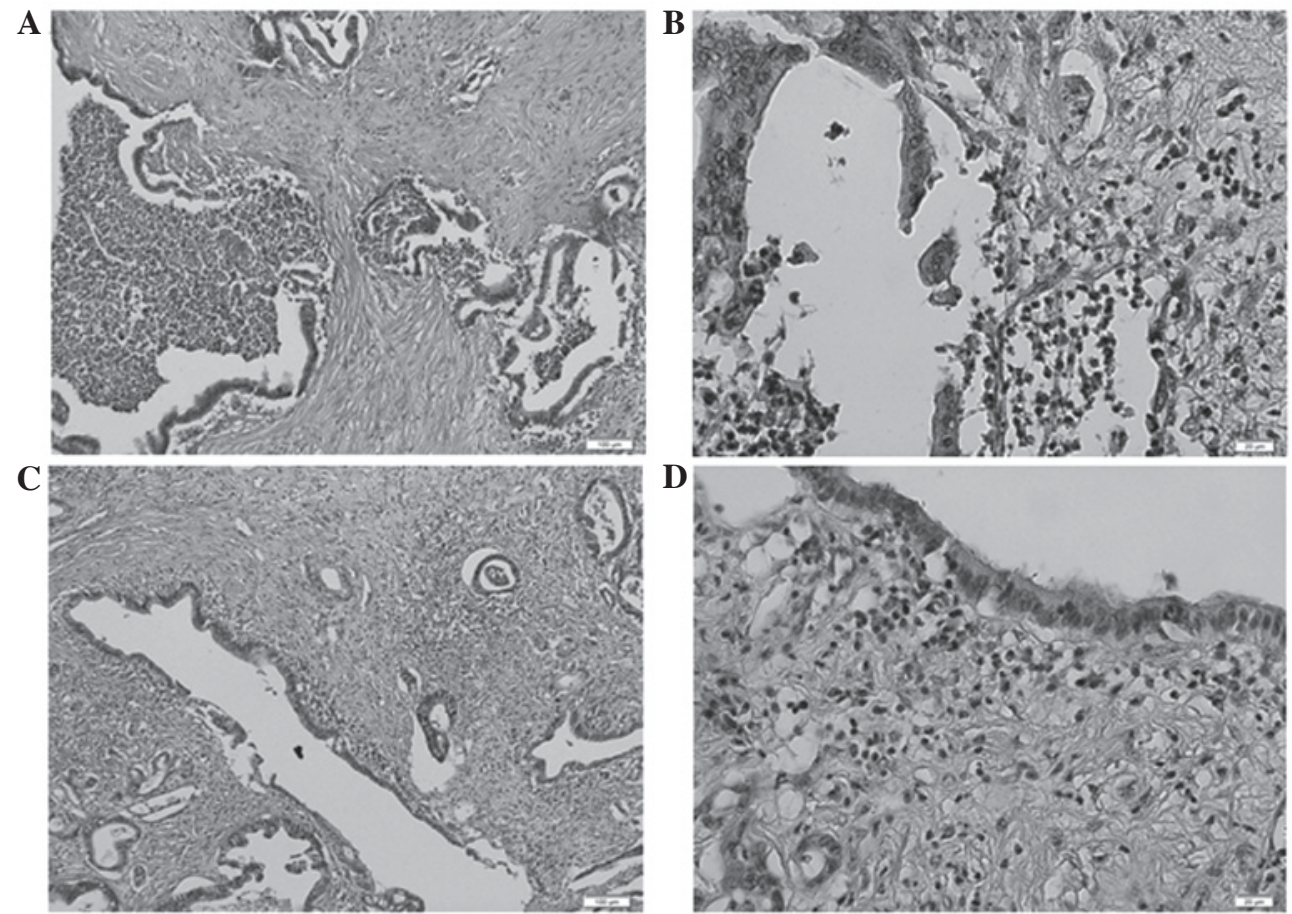

Figure 2. Representative images of patient specimens with a particularly high neutrophil to lymphocyte ratio. The pancreatic ductal adenocarcinoma tissue contained masses of neutrophils: (A) x100 magnification; (B) x400 magnification (stain, hematoxylin and eosin). Lymphoid follicles were not observed in the stromal tissue adjacent to the tumor: (C) x100 magnification; (D) x400 magnification (stain, hematoxylin and eosin).

A

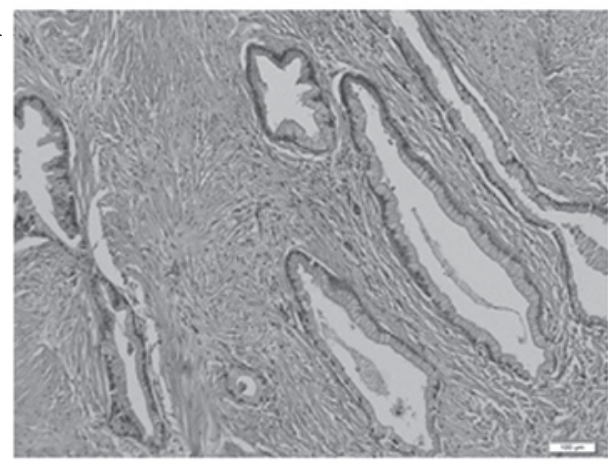

C

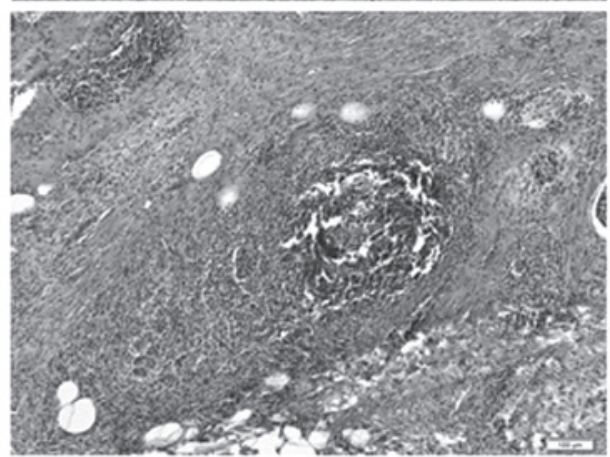

B

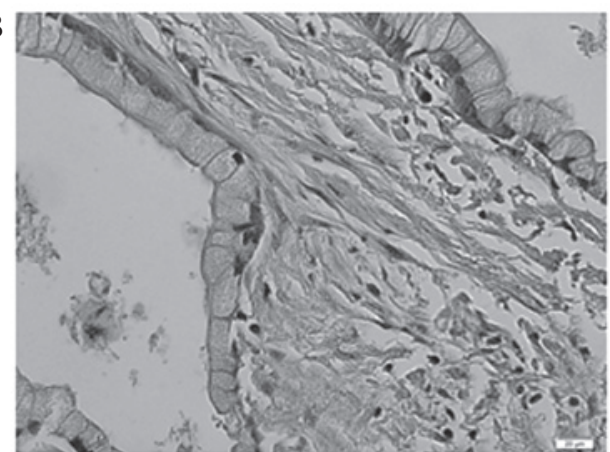

D

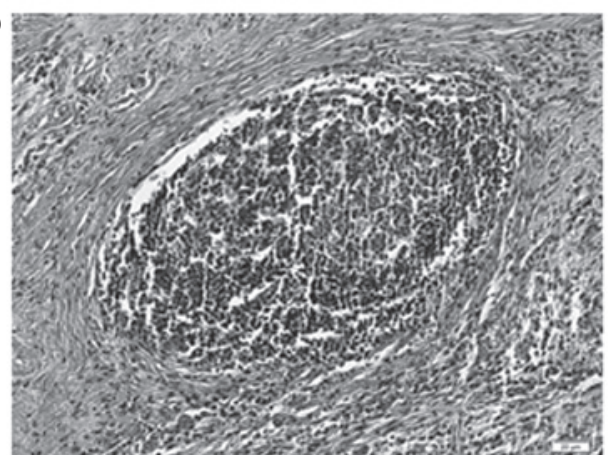

Figure 3. Representative images of patient specimens with a particularly low neutrophil to lymphocyte ratio. The pancreatic ductal adenocarcinoma did not contain any neutrophils: (A) x100 magnification; (B) x400 magnification (stain, hematoxylin and eosin). The lymphoid follicles were formed in the stromal tissue adjacent to the tumor: (C) x100 magnification; (D) x400 magnification (stain, hematoxylin and eosin).

hematological factors and the pathological response to preoperative therapies, the patients who underwent preoperative treatments were divided into a poor response group (Evans grade I or IIa) and a good response group (Evans grade IIb or III). The background clinical and histopathological factors were compared between the two groups (Table II). The mean NLR value was significantly higher in the poor response group than in the good response group, whereas the other examined factors demonstrated no significant differences between the two groups. 
Optimal cut-off level of the pre-therapeutic NLR. An ROC curve was prepared by plotting sensitivity values against specificity values at the indicated NLR (Fig. 1). From the ROC curve, the optimal cut-off level of the pre-therapeutic NLR for predicting pathological non-responders (Evans I/IIa) was determined to be 2.2 .

$N L R$ is an independent predictive factor for pathological response. The evaluation of predictive factors for the pathological response among clinical information were assessed, including a number of prognostic markers that have been previously reported: NLR (23), PLR (24), mGPS (21) and PNI (22). Upon univariate analysis, NLR and mGPS were determined to be significantly associated with the pathological response, whilst the other prognostic markers were not (Table IIIA). Furthermore, multivariate analysis identified NLR as a significant and independent predictive factor (Table IIIB). NLR and mGPS are both closely related to inflammation; therefore, mGPS was not included in the multivariate analysis. Subsequently, the association between the blood NLR value and features of the corresponding clinical specimen were examined. Notably, numerous masses of neutrophils were detected in pancreatic ductal adenocarcinoma in cases with particularly high NLRs (Fig. 2), and the formation of lymphoid follicles in the stromal tissue adjacent to the tumor was observed in cases with particularly low NLRs (Fig. 3). This finding indicated that the NLR determined by blood examination at least partially reflected the state of the inflammation in the corresponding clinical specimens.

Finally, the predictive ability of the NLR with regard to the pathological response to preoperative therapies was evaluated. Table IV shows the prediction of pathological responses using the pre-treatment NLR values $(\geq 2.2 /<2.2)$. The NLR was revealed to be a significant predictive marker of pathological response $(\mathrm{P}=0.00699)$ : The good response rates were $9.1 \%$ in patients with an NLR $\geq 2.2$, and $44.1 \%$ in patients with an NLR $<2.2$.

\section{Discussion}

The NLR, which is an inexpensive and widely available blood test, has been demonstrated to be an important prognostic predictor in numerous types of cancer, including colorectal cancer (29), gastric cancer (30), ovarian cancer (31), intrahepatic cholangiocarcinoma (32), hepatocellular carcinoma (33), and pancreatic cancer (34). Furthermore, it has been reported that the NLR is correlated with the pathological response to preoperative therapy $(35,36)$. However, there have been no reports focusing on the association between high NLR and poor response to neoadjuvant therapies in pancreatic cancer. In the present study, various pre-treatment hematological factors related to pathological response were assessed.

Biologically, the significance of high neutrophil counts in malignant tumors is based on a combination of T-cell suppression via the production of certain active substances, such as reactive oxygen species, nitric oxide and arginase $(37,38)$, and stimulation of tumor angiogenesis through the production of IL-8, vascular endothelial growth factor, elastase and matrix metalloproteinase (39-41). By contrast, previous reports have suggested that a high number of tumor-infiltrating lymphocytes was strongly associated with favorable outcomes in patients with various types of cancer $(42,43)$. Furthermore, lymphocytes, particularly $\mathrm{T}$ cells, are considered to play a central role in antitumor immunity; thus, the lymphocyte count is thought to reflect the ability of the body to eliminate tumor cells (44).

Recently, a number of combination therapies, consisting of preoperative chemoradiotherapy, surgery and postoperative chemotherapy, have been used in clinical trials, which were found to improve the poor prognosis of pancreatic cancer $(27,45)$. In cases where combined therapies are used, it is essential to identify predictors of response to preoperative therapy in order to inform the assessment of risk and patient counselling. Similar multimodal therapies have been used for the treatment of esophageal and rectal cancers, as well as pancreatic cancer; NLR has been reported to be a useful and available predictive marker associated with pathological response to neoadjuvant chemotherapy or preoperative chemoradiotherapy in esophageal and rectal cancers, respectively $(35,36)$. However, to the best of our knowledge, the present study is the first to demonstrate that pre-treatment NLR is significantly higher in pancreatic cancer patients who respond poorly to treatment compared with that of patients who exhibit a favorable response. NLR was identified as a significant independent risk factor among pre-treatment clinical factors, and the ratio of pathologically favorable responses was significantly lower in patients with an NLR $\geq 2.2$ compared with that of the patients with an NLR $<2.2$. This finding suggests that pre-treatment NLR may be used to predict which patients will benefit from preoperative therapy.

In conclusion, pre-treatment NLR is an independent predictive marker of the pathological response to preoperative therapy in pancreatic cancer patients. However, long term analysis to investigate the association between pre-treatment NLR and disease free or overall survival has not yet been performed. Thus, further large scale, long-term studies are required to establish a cut-off value for the NLR which may be used to guide preoperative treatment choices.

\section{Acknowledgements}

The authors would like to thank Professor Eiichi Morii and Dr Satoshi Nojima (Department of Pathology, Graduate School of Medicine, Osaka University) for evaluating the pathological findings.

\section{References}

1. Siegel R, Naishadham D and Jemal A: Cancer statistics, 2012. CA Cancer J Clin 62: 10-29, 2012.

2. Neoptolemos JP, Stocken DD, Friess H, Friess H, Bassi C, Dunn JA, Hickey H, Beger H, Fernandez-Cruz L, Dervenis C, et al: A randomized trial of chemoradiotherapy and chemotherapy after resection of pancreatic cancer. N Engl J Med 350: 1200-1210, 2004.

3. Oettle H, Neuhaus P, Hochhaus A, Hartmann JT, Gellert K, Ridwelski K, Niedergethmann M, Zülke C, Fahlke J, Arning MB, et al: Adjuvant chemotherapy with gemcitabine and long-term outcomes among patients with resected pancreatic cancer: The CONKO-001 randomized trial. JAMA 310: 1473-1481, 2013.

4. Eguchi H, Nagano H, Tanemura M, Takeda Y, Marubashi S, Kobayashi S, Kawamoto K, Wada H, Hama N, Akita H, et al: Preoperative chemoradiotherapy, surgery and adjuvant therapy for resectable pancreatic cancer. Hepatogastroenterology 60: 904-911, 2013 
5. Ohigashi $\mathrm{H}$, Ishikawa $\mathrm{O}$, Eguchi $\mathrm{H}$, Takahashi $\mathrm{H}$, Gotoh $\mathrm{K}$ Yamada T, Yano M, Nakaizumi A, Uehara H, Tomita Y and Nishiyama K: Feasibility and efficacy of combination therapy with preoperative full-dose gemcitabine, concurrent three-dimensional conformal radiation, surgery and postoperative liver perfusion chemotherapy for T3-pancreatic cancer. Ann Surg 250: 88-95, 2009.

6. Evans DB, Varadhachary GR, Crane $\mathrm{CH}$, Sun CC, Lee JE, Pisters PW, Vauthey JN, Wang H, Cleary KR, Staerkel GA, et al: Preoperative gemcitabine-based chemoradiation for patients with resectable adenocarcinoma of the pancreatic head. J Clin Oncol 26 3496-3502, 2008

7. Takahashi H, Ohigashi H, Gotoh K, Marubashi S, Yamada T, Murata M, Ioka T, Uehara H, Yano M and Ishikawa O: Preoperative gemcitabine-based chemoradiation therapy for resectable and borderline resectable pancreatic cancer. Ann Surg 258: 1040-1050, 2013.

8. Matsuda T, Taniguchi F, Minato $\mathrm{H}$, Nomura $\mathrm{H}$, Tsuda $\mathrm{T}$ and Aikawa I: Successful resection of advanced pancreatic tail cancer after neoadjuvant gemcitabine chemotherapy: Report of a case. Surg Today 36: 754-757, 2006

9. Fortner JG, Klimstra DS, Senie RT and Maclean BJ: Tumor size is the primary prognosticator for pancreatic cancer after regional pancreatectomy. Ann Surg 223: 147-153, 1996.

10. Griffanti-Bartoli F, Arnone GB, Ceppa P, Ravera G, Carrabetta S and Civalleri D: Malignant tumors in the head of the pancreas and the periampullary region. Diagnostic and prognostic aspects. Anticancer Res 14: 657-666, 1994.

11. Raut CP, Tseng JF, Sun CC, Wang H, Wolff RA, Crane CH, Hwang R, Vauthey JN, Abdalla EK, Lee JE, et al: Impact of resection status on pattern of failure and survival after pancreaticoduodenectomy for pancreatic adenocarcinoma. Ann Surg 246: 52-60, 2007.

12. Ozaki H, Hiraoka T, Mizumoto R, Matsuno S, Matsumoto Y, Nakayama T, Tsunoda T, Suzuki T, Monden M, Saitoh Y, et al: The prognostic significance of lymph node metastasis and intrapancreatic perineural invasion in pancreatic cancer after curative resection. Surg Today 29: 16-22, 1999.

13. Dvorak HF: Tumors: Wounds that do not heal. Similarities between tumor stroma generation and wound healing. N Engl J Med 315: 1650-1659, 1986.

14. Balkwill F and Mantovani A: Inflammation and cancer: Back to Virchow? Lancet 357: 539-545, 2001.

15. Coussens LM and Werb Z: Inflammation and cancer. Nature 420: $860-867,2002$

16. Mantovani A, Allavena P, Sica A and Balkwill F: Cancer-related inflammation. Nature 454: 436-444, 2008.

17. Grivennikov SI, Greten FR and Karin M: Immunity, inflammation and cancer. Cell 140: 883-899, 2010.

18. Bambury RM, Teo MY, Power DG, Yusuf A, Murray S Battley JE, Drake C, O'Dea P, Bermingham N, Keohane C, et al: The association of pre-treatment neutrophil to lymphocyte ratio with overall survival in patients with glioblastoma multiforme. J Neurooncol 114: 149-154, 2013.

19. Fox P, Hudson M, Brown C, Lord S, Gebski V, De Souza P and Lee CK: Markers of systemic inflammation predict survival in patients with advanced renal cell cancer. Br J Cancer 109: 147-153, 2013.

20. Shimazaki J, Goto Y, Nishida K, Tabuchi T, Motohashi G, Ubukata $\mathrm{H}$ and Tabuchi $\mathrm{T}$ : In patients with colorectal cancer, preoperative serum interleukin-6 level and granulocyte/ lymphocyte ratio are clinically relevant biomarkers of long-term cancer progression. Oncology 84: 356-361, 2013.

21. Proctor MJ, Morrison DS, Talwar D, Balmer SM, O'Reilly DS Foulis AK, Horgan PG and McMillan DC: An inflammation-based prognostic score (mGPS) predicts cancer survival independent of tumour site: A Glasgow Inflammation Outcome Study. Br J Cancer 104: 726-734, 2011.

22. Onodera T, Goseki N and Kosaki G: Prognostic nutritional index in gastrointestinal surgery of malnourished cancer patients. Nihon Geka Gakkai Zasshi 85: 1001-1005, 1984 (In Japanese).

23. Garcea G, Ladwa N, Neal CP, Metcalfe MS, Dennison AR and Berry DP: Preoperative neutrophil-to-lymphocyte ratio (NLR) is associated with reduced disease-free survival following curative resection of pancreatic adenocarcinoma. World J Surg 35: 868-872, 2011.

24. Smith RA, Bosonnet L, Raraty M, Sutton R, Neoptolemos JP, Campbell F and Ghaneh P: Preoperative platelet-lymphocyte ratio is an independent significant prognostic marker in resected pancreatic ductal adenocarcinoma. Am J Surg 197: 466-472, 2009
25. Sobin LH, Gospodarowicz MK and Wittekind C (eds). TNM Classification of Malignant Tumors. 7th edition. Wiley-Blackwell, Oxford, 2010

26. Buzby GP, Mullen JL, Matthews DC, Hobbs CL and Rosato EF: Prognostic nutritional index in gastrointestinal surgery. Am J Surg 139: 160-167, 1980

27. Eguchi H, Nagano H, Kobayashi S, Kawamoto K, Wada H, Hama N, Tomimaru Y, Akita H, Sakai D, Satoh T, et al: A phase I trial of combination therapy using gemcitabine and S-1 concurrent with full-dose radiation for resectable pancreatic cancer. Cancer Chemother Pharmacol 73: 309-315, 2014.

28. Evans DB, Rich TA, Byrd DR, Cleary KR, Connelly JH, Levin B, Charnsangavej C, Fenoglio CJ and Ames FC: Preoperative chemoradiation and pancreaticoduodenectomy for adenocarcinoma of the pancreas. Arch Surg 127: 1335-1339, 1992.

29. Kishi Y, Kopetz S, Chun YS, Palavecino M, Abdalla EK and Vauthey JN: Blood neutrophil-to-lymphocyte ratio predicts survival in patients with colorectal liver metastases treated with systemic chemotherapy. Ann Surg Oncol 16: 614-622, 2009.

30. Jiang N, Deng JY, Liu Y, Ke B, Liu HG and Liang H: The role of preoperative neutrophil-lymphocyte and platelet-lymphocyte ratio in patients after radical resection for gastric cancer. Biomarkers 19: 444-451, 2014.

31. Cho H, Hur HW, Kim SW, Kim SH, Kim JH, Kim YT and Lee K: Pre-treatment neutrophil to lymphocyte ratio is elevated in epithelial ovarian cancer and predicts survival after treatment. Cancer Immunol Immunother 58: 15-23, 2009.

32. Gomez D, Morris-Stiff G, Toogood GJ, Lodge JP and Prasad KR: Impact of systemic inflammation on outcome following resection for intrahepatic cholangiocarcinoma. J Surg Oncol 97: 513-518, 2008.

33. Gomez D, Farid S, Malik HZ, Young AL, Toogood GJ, Lodge JP and Prasad KR: Preoperative neutrophil-to-lymphocyte ratio as a prognostic predictor after curative resection for hepatocellular carcinoma. World J Surg 32: 1757-1762, 2008.

34. Stotz M, Gerger A, Eisner F, Szkandera J, Loibner H, Ress AL, Kornprat P, AlZoughbi W, Seggewies FS, Lackner C, et al: Increased neutrophil-lymphocyte ratio is a poor prognostic factor in patients with primary operable and inoperable pancreatic cancer. Br J Cancer 109: 416-421, 2013.

35. Sato H, Tsubosa Y and Kawano T: Correlation between the pretherapeutic neutrophil to lymphocyte ratio and the pathologic response to neoadjuvant chemotherapy in patients with advanced esophageal cancer. World J Surg 36: 617-622, 2012

36. Dou X, Wang RB, Yan HJ, Jiang SM, Meng XJ, Zhu KL, Xu XQ and $\mathrm{Mu} \mathrm{DB}$ : Circulating lymphocytes as predictors of sensitivity to preoperative chemoradiotherapy in rectal cancer cases. Asian Pac J Cancer Prev 14: 3881-3885, 2013.

37. Müller I, Munder M, Kropf P and Hänsch GM: Polymorphonuclear neutrophils and T lymphocytes: Strange bedfellows or brothers in arms? Trends Immunol 30: 522-530, 2009.

38. Rodriguez PC, Ernstoff MS, Hernandez C, Atkins M, Zabaleta J, Sierra R and Ochoa AC: Arginase I-producing myeloid-derived suppressor cells in renal cell carcinoma are a subpopulation of activated granulocytes. Cancer Res 69: 1553-1560, 2009.

39. Shamamian P, Schwartz JD, Pocock BJ, Monea S, Whiting D, Marcus SG and Mignatti P: Activation of progelatinase A (MMP-2) by neutrophil elastase, cathepsin $\mathrm{G}$ and proteinase-3: A role for inflammatory cells in tumor invasion and angiogenesis. J Cell Physiol 189: 197-206, 2001.

40. Scapini P, Nesi L, Morini M, Tanghetti E, Belleri M, Noonan D, Presta M, Albini A and Cassatella MA: Generation of biologically active angiostatin kringle 1-3 by activated human neutrophils. J Immunol 168: 5798-5804, 2002.

41. Di Carlo E, Forni G and Musiani P: Neutrophils in the antitumoral immune response. Chem Immunol Allergy 83: 182-203, 2003.

42. Galon J, Costes A, Sanchez-Cabo F, Kirilovsky A, Mlecnik B, Lagorce-Pagès C, Tosolini M, Camus M, Berger A, Wind $\mathrm{P}$, et al: Type, density and location of immune cells within human colorectal tumors predict clinical outcome. Science 313: 1960-1964, 2006.

43. Morris M,Platell C and Iacopetta B: Tumor-infiltrating lymphocytes and perforation in colon cancer predict positive response to 5-fluorouracil chemotherapy. Clin Cancer Res 14: 1413-1417, 2008.

44. Galon J, Pagès F, Marincola FM, Thurin M, Trinchieri G, Fox BA, Gajewski TF and Ascierto PA: The immune score as a new possible approach for the classification of cancer. J Transl Med 10: 1, 2012.

45. Motoi F, Unno M, Takahashi H, et al: Influence of preoperative anti-cancer therapy on resectability and perioperative outcomes in patients with pancreatic cancer: Project study by the Japanese Society of Hepato-Biliary-Pancreatic Surgery. J Hepatobiliary Pancreat Sci 21: 148-158, 2014. 